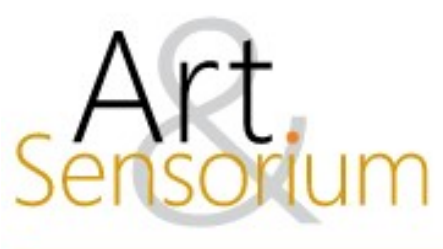

\title{
SOFIA DYMINSKI E AS “MOÇAS DA ILHA”: HISTÓRIA, ARTE E GÊNERO
}

\author{
https://doi.org/10.33871/23580437.2021.8.1.030-047
}

Mauricio Marcelino Lima ${ }^{1}$

\begin{abstract}
RESUMO: Este trabalho apresenta algumas reflexões acerca da arte produzida por mulheres e de como o estudo das categorias de gênero pode utilizar-se dessas produções para compreender as formas de ação feminina, mesmo em contextos em que a militância feminista não tenha ocorrido de maneira incisiva, mas que já havia iniciativas implícitas nessas composições que davam luz às temáticas de gênero. Deste modo, faremos um recorte na obra de Sofia Dyminski, onde analisaremos a pintura Moças da Ilha (1964). Observaremos, dessa forma, como algumas subjetividades femininas estão contidas na composição, as relações com a produção da Arte Moderna Paranaense que passava nesta época por um processo de ruptura, com a superação dos ideais canônicos, o alargamento da concepção de estética (beleza), inclusive com a cisão ao Movimento Paranista, compreendendo a obra artística como fonte histórica. Nesse sentido, a partir da Nova História e da ampliação dos campos de pesquisa dos historiadores, é possível reconhecermos o objeto artístico, neste caso a pintura, como uma narrativa (imagética) que comunica experiências, memórias e/ou sentimentos, ocorridos no tempo e no espaço, seja de modo direto ou metaforizado.
\end{abstract}

Palavras-chave: Sofia Dyminski; Arte Moderna Paranaense; Arte e Gênero; Moças da Ilha.

\begin{abstract}
This work presents some reflections about the art produced by women and how the study of gender categories can use these productions to understand the forms of female action, even in contexts where feminist militancy has not occurred incisively, but that there were already initiatives implicit in these compositions that gave light to gender themes. Thus, we will make a cut in the work of Sofia Dyminski, where we will analyze the painting Moças da Ilha (1964). We will observe, in this way, how some feminine subjectivities are contained in the composition, the relations with the production of the Modern Art of Paraná that was going through a rupture process, with the overcoming of the canonical ideals, the widening of the conception of aesthetics (beauty) including with the split of the Paranista Movement, understanding the artistic work as a historical source. In this sense, from the New History and the expansion of the historians' research fields, it is possible to recognize the artistic object, in this case painting, as a narrative (imagery) that communicates experiences, memories and / or feelings, occurred in time and in space, either directly or metaphorically.
\end{abstract}

Keywords: Sofia Dyminski; Modern Art from Paraná; Art and Gender; Girls from the Island.

\footnotetext{
${ }^{1}$ Professor do Instituto Federal do Paraná, Campus Cascavel. Currículo (CV: http://lattes.cnpq.br/7371804553836871): Doutorando em História PPGH/Unioeste (2019-2023), mestre em História pela Universidade Estadual de Maringá (2016). Leciona as Disciplinas de Artes I e Artes II nos cursos técnicos Integrados em Informática, Análises Químicas e Edificações. Email: Mauricio.lima@ifpr.edu.br; ORCID: https://orcid.org/0000-0002-8220-2014
} 
RESUMEN: Este trabajo presenta algunas reflexiones sobre el arte producido por las mujeres y cómo el estudio de las categorías de género puede usar estas producciones para comprender las formas de acción femenina, incluso en contextos donde la militancia feminista no ha ocurrido incisivamente , pero que ya había iniciativas implícitas en estas composiciones que dieron luz a los temas de género. Así, haremos un corte en la obra de Sofia Dyminski, donde analizaremos la pintura Moças da Ilha (1964). Observaremos, de esta manera, cómo algunas subjetividades femeninas están contenidas en la composición, las relaciones con la producción del Arte Moderno de Paraná que atravesaba un proceso de ruptura, con la superación de los ideales canónicos, el ensanchamiento de la concepción. de la estética (belleza), incluso con la escisión del Movimiento Paranista, entendiendo la obra artística como fuente histórica. En este sentido, a partir de la Nueva Historia y la expansión de los campos de investigación de los historiadores, es posible reconocer el objeto artístico, en este caso la pintura, como una narrativa (imaginería) que comunica vivencias, recuerdos y / o sentimientos, ocurridos en en el tiempo y en el espacio, ya sea directa o metafóricamente.

Palabras clave: Sofía Dyminski; Arte moderno de Paraná; Arte y género; Niñas de la isla.

\section{Introdução}

No século XX, a produção historiográfica passa por um processo de ampliação em suas áreas de estudo, possibilitado pela Nova História, quebrando os parâmetros da História tradicional, até então preocupada em analisar as questões relacionadas às conjunturas econômicas e demográficas. Nesse viés, preocupou-se com as questões relacionadas ao social e a cultura, dando espaço, dentro da disciplina, para estudos e objetos que dialogam com outras áreas, como a Sociologia e a Psicologia ${ }^{2}$. É nesse cenário que a História da Arte e os estudos da categoria de gênero ganham espaço, possibilitando uma análise sobre as relações que envolvem a produção estética e a história das mulheres, com temáticas ligadas à memória, a identidade e as subjetividades.

Nesta senda, com a articulação entre arte, história e gênero, este ensaio pretende analisar a obra Moças da Ilha, (1964) de Sofia Dyminski, procurando refletir de que modo a composição pode levantar questionamentos acerca das relações de gênero na sociedade paranaense da segunda metade do século XX. Seria possível identificar alguma forma de agência da artista em abordar subjetividades femininas? A Arte Moderna como uma forma de ruptura, não só com os cânones acadêmicos, que possibilitou novas experimentações estéticas e temáticas, mas também com uma abordagem crítica da sociedade, resultado dos processos de transformação social, econômico e cultural, poderia ter contribuído para a abordagem das relações de gênero? Seria possível a arte contribuir com a tessitura da história, neste caso, a história das artistas modernas paranaenses?

Essas são algumas das perguntas que nos indagam quando pensamos na produção de artistas mulheres e de como as representações artísticas poderiam ser utilizadas para compreendermos a realidade e as subjetividades femininas, suas experiências e os modos como elas reagiam diante de uma sociedade hierarquizada, de dominação masculina. Para Alfredo Bosi, a arte pode ser uma "percepção analógica de certos perfis da experiência" (BOSI, 2004, p. 30), que deste modo reverbera e interpreta a realidade, ou ainda seus desdobramentos, como os sentimentos e estados mentais que tais acontecimentos tiveram potencial de gerar.

\footnotetext{
${ }^{2}$ BURKE, P. Abertura: A Nova História, seu passado e seu futuro. In: BURKE, P. A Escrita da História. São Paulo: Unesp, 1992. Cap. 01, p. 07-37; CHARTIER, R. A beira da Falésia: a história entre incertezas e inquietudes. $1^{\mathrm{a}}$. ed. Porto Alegre: Universidade Federal do Rio Grande do Sul, 2002
} 


\section{Arte Moderna e a abordagem das temáticas de gênero}

A produção da arte moderna não é um acontecimento simplesmente datado, onde a partir de um dado momento estivera contrariando os cânones artísticos que lhe antecederam, ela faz parte de um processo muito maior que possibilitou pensar e experimentar a produção do objeto artístico de modos diferentes, e também a compreensão do que era considerado belo - estético - como objeto artístico em um determinado tempo e lugar. Esteve ligada a várias e abruptas transformações ocorridas, sobretudo, a partir das revoluções industriais e da revolução política, com a defesa da democracia, a mudança dos processos de produção que deslocaram parte da população para a zona urbana, resultando em novas experiências e relações sociais, econômicas e de trabalho, especialmente na Europa e América ${ }^{3}$. Além de novas tecnologias de captura e reprodução da imagem, competindo, inclusive, com a função do artista, de representar (de maneira naturalista/realista) fatos, acontecimentos, retratos, a partir do século XIX, como a fotografia e o cinema.

Segundo Meira, a compreensão da arte esteve desde o início da história da filosofia, ligada a noção de beleza, ou melhor, ao conceito de estética, do que seria considerado belo e sua sensação, sendo que ao longo dos tempos tentou-se ampliar a compreensão da arte, como "as teorias mais recentes, que não remetem à arte só a beleza, nem só a sensação e o sentir” (MEIRA, 2006, p. 13).

Nessa perspectiva, a arte moderna continua a ampliar essa noção de produção do objeto artístico, onde novas formas de representação, como a exploração de materiais diferentes, usos da luminosidade, cores e formas, são mensurados de modos antes não compreendidos, tanto pelos cânones e suas instituições, como pelos espectadores. A arte moderna, nesse ínterim, não se tratou só da superação de modelos (formais) predeterminados, mas na própria concepção do que é a beleza das concepções ideológicas do mundo e sociedade - e de como ela pode ser compreendida de maneiras distintas podendo ser dinâmica e mutável. A compreensão da estética na modernidade, não é mais estabelecida pela dicotomia belo e não belo, e/ou padrões que disciplinam o que é a beleza; a estética "define-se muito mais através de uma ação humana do que através do belo, harmônico ou da transcendência divina" (MEIRA, 2006, p. 16). Dessa forma:

Criar torna-se um ato, evoca os mecanismos psíquicos e mentais tanto do criador quanto do espectador, uma vez que resulta de um processo perceptivo. De artesão, talentoso e hábil, no Renascimento, como um imitador da natureza, do homem de Deus, o artista do século XX, submete-se ao racionalismo em detrimento das faculdades sensíveis, submete-se a fantasia e à imaginação em detrimento do gosto (MEIRA, 2006, p. 16)

A arte moderna, então, está atrelada a esses mecanismos psíquicos e mentais, que envolvem criador e espectador, superando a noção de que o artista era apenas um imitador da natureza. Os teóricos e os artistas da modernidade continuam expandindo a noção de estética (belo), bem como a ampliação de temáticas, mesmo aquelas que pudessem contrariar os interesses de quem detinha o poder, como as questões sociais, o questionamento de decisões políticas e de aspectos econômicos, e até mesmo a produção de uma arte ligada ao inconsciente, onde era possível explorar o mundo onírico e a imaginação. Ademais, expande-se, assim, as formas de pensar e de idealizar o objeto artístico, propondo novas maneiras de produzir e analisar a obra.

A arte, desse modo, propõe uma ampliação na relação entre o criador e o público, ela não é mais concebida apenas a partir de uma série de normatizações éticas e formais e por ideologias constituídas pelos detentores do poder - e que deveriam, antes, serem validadas como obra de arte —, pelas

\footnotetext{
${ }^{3}$ Ver: JANSON, H. W.; JANSON, A. F. Iniciação a história da arte. São Paulo: Martins Fontes, 1996. p. 302
} 
instituições políticas e sociais que faziam a disciplina. Ela desloca o observador, que antes era um agente passivo (observador), onde apenas identificava os elementos da obra; convida-o, agora, a refletir, analisar e problematizar o objeto artístico representado pelo artista que era, antes, o único agente ativo. "A razão estética do século XX se construiu na estética intermediária, entre a razão e a imaginação, entre o entendimento e a sensibilidade, e é o espectador o sujeito que realiza a harmonia entre as faculdades mentais" (MEIRA, 2006, p. 16).

Desse modo, o artista e o público têm uma relação integrada, o que ele comunica será analisado refletido e considerado pelo espectador, que a partir de suas experiências e interpretações, poderá compreender as subjetividades apresentadas pela obra, de múltiplas maneiras, e ainda somar essas subjetividades a suas próprias experiências, considerando os significados elaborados pelo artista, mas atrelando, também, seus próprios significados a essas representações. Isso se torna possível justamente pelo potencial subjetivo e comunicativo entre esses dois agentes.

Não existe mais a primazia de um modelo estético rígido de produção e interpretação do objeto artístico, tampouco um gênero de arte melhor que o outro ou uma temática proibida - essas cisões com as normas institucionais da disciplina, durante muito tempo cerceavam as mulheres, por exemplo, de abordarem determinados gêneros como a pintura histórica e o nu, considerando o artista homem como um gênio e as mulheres como um objeto do olhar e da criatividade masculina, ao invés de visualizá-las como produtoras culturais ${ }^{4}$.

Neste sentido, visualizo uma proximidade e possibilidade de análise muito interessante entre a atividade artística e histórica, especialmente quando os historiadores rompem com o topos da História Magista Vitae, amplamente analisada e questionada por Koselleck, que discutiu a história como exemplo para o futuro ${ }^{5}$.

A arte, embora tenha funções e modos de configuração como disciplina, distintos da história, nesse ponto, alinha-se com a superação da racionalidade de uma produção que deveria ser usada como modelo (canônica) para então explorar formas diferentes de experimentação estética, considerando as transformações sociais, culturais, econômicas e institucionais. Na história da arte, por exemplo, as mulheres não tinham o mesmo tratamento que o homem, eram marginalizadas; e na disciplina histórica elas também não haviam, ainda, conquistado o mesmo valor que os historiadores homens. Foi com o decorrer do século XX, e as transformações ocorridas a partir dos movimentos feministas, que foi possível pensar a produção da história e da arte sob uma nova perspectiva, onde o gênero não pesasse negativamente às mulheres, mas que estivessem em um patamar de igualdade no reconhecimento de suas produções.

É a partir dessa nova forma de produção, tanto da história (Geschichte) ${ }^{6}$, como da arte, que o sujeito se ocupa das experiências contemporâneas como eventos únicos, buscando problematizá-las, compreendê-las e interpretá-las, aprendendo com elas, mas tendo a ciência de que não são receitas a serem seguidas, pois, envolvem uma outra série de eventos e problematizações. Nesse sentido, Hartog (2014, p. 186) chama a atenção para compreendermos o historiador como um lugar de memória "o ponto de partida de sua operação historiográfica: converter a memória menos como conteúdo do que como forma, em modo de questionamento histórico e de escrita da história".

Nessa senda, quando a imagem pictórica representa memórias - ou perfis de experiência, como diria Bosi -, ela pode contribuir para a tessitura da história. Basta cotejá-la com outras fontes para melhor

\footnotetext{
${ }^{4}$ Ver: POLLOCK, G. Visión y diferencia: feminismo, feminidad e historias del arte. Buenos Aires: Fiordo, 2019.

5“A história pode conduzir ao relativo aperfeiçoamento moral ou intelectual de seus contemporâneos e de seus pósteros, mas somente se e enquanto os pressupostos para talforem basicamente os mesmos". KOSELLECK, R. Futuro passado: contribuição à semântica dos tempos históricos. Rio de Janeiro: PUC-Rio, 2006. p. 43.

6"A história (Geschichte) como acontecimento único" é um fenômeno semântico que abrange a nossa experiência histórica moderna". KOSELLECK, R. Futuro passado: contribuição à semântica dos tempos históricos. Rio de Janeiro: PUC-Rio, 2006. p.48 e 119.
} 
compreender as intenções do artista em cristalizar, por intermédio da imagem, tais formas, sujeitos, cores e acontecimentos, pois embora a arte seja subjetiva ela é, sobretudo, expressão, e o artista comunica a partir de um lugar e de um contexto.

O historiador da arte Ernest Gombrich (2007, p. 306) salienta que "há mais em comum entre a linguagem das palavras e a representação visual do que às vezes admitimos" e que "a imagem visual, funciona não só a serviço da descrição objetiva, concreta, e da emoção subjetiva, mas também naquela vasta área entre esses dois extremos, onde a linguagem de todo dia transmite tanto os fatos quanto o tom emotivo de uma experiência" (p. 310).

Tanto na história quanto na arte, é a partir dessas reflexões e da nova abordagem, que temáticas como a história das mulheres e a categoria de gênero puderam ser analisadas dentro da Nova História. Sendo assim, a obra de arte e a análise aqui proposta, busca aproximar essas disciplinas, compreendendo como a imagem pictórica pode evidenciar aspectos importantes da participação feminina na sociedade, trazendo à tona, novas subjetividades e formas de analisar suas relações sociais.

Deste modo, é importante destacar algumas reflexões pautadas pela filósofa Judith Butler e pela historiadora Joan Scott. Ambas trabalham com a história das mulheres e a categoria de gênero, trazendo contribuições significativas e referenciais para essa temática.

Segundo Scott, a história das mulheres, nas últimas décadas, já aparece como um campo definível, abordado pela academia, e que embora seja resultado da participação e análise da atuação de movimentos feministas, com amplo teor político e de militância a partir do final da década de 1970, afastou-se da política em busca de ampliar seus "questionamentos, documentando todos os aspectos da vida das mulheres no passado, e dessa forma, adquiriu uma energia própria" (SCOTT, 1992, p. 64). Ou seja, Scott chama a atenção para todas as possibilidades de análise da atuação feminina na história, não girando apenas em torno dos movimentos feministas e da questão política, mas "a emergência da história das mulheres como um campo de estudo envolve, nesta interpretação, uma evolução do feminismo para as mulheres e daí para o gênero; ou seja, da política para a história especializada e daí para a análise" (SCOTT, 1992, p. 65).

Judith Butler, nesse viés, aproximando-se de Scott, realiza uma crítica ao teor ideológico e universalizante da identidade feminina, muitas vezes presentes nesses movimentos. Sobre isso a autora comenta:

Em sua essência, a teoria feminista tem presumido que existe uma identidade definida, compreendida pela categoria de mulheres, que não só deflagra os interesses e objetivos feministas no interior de seu próprio discurso, mas constitui o sujeito mesmo em nome de quem a representação política é almejada. Mas política e representação são termos polêmicos. Por um lado, a representação serve como termo operacional no seio de um processo político que busca estender visibilidade e legitimidade às mulheres como sujeitos políticos; por outro lado, a representação é a função normativa de uma linguagem que revelaria ou distorceria o que é tido como verdadeiro sobre a categoria de mulheres (BUTLER, 2003, p. 17-18).

Essa compreensão da categoria de mulheres pode se mostrar problemática, embora seja compreensível em um primeiro momento, pois sua intenção é dar visibilidade política a partir da teoria feminista. No entanto, ela adverte sobre os efeitos negativos dos sistemas jurídicos de poder, retomando Foucault, pois estes acabam limitando e normatizando os indivíduos a uma estrutura política. Dessa maneira, "a crítica feminista também deve compreender como a categoria das 'mulheres', o sujeito do feminismo, é produzido e reprimido pelas mesmas estruturas de poder por intermédio das quais busca-se a emancipação" (BUTLER, 2003, p. 19). Partindo das reflexões de Butler, é importante compreender que não há uma linearidade na constituição do sujeito feminino, e que as suas formas de ser e estar no mundo podem ocorrer de múltiplas maneiras. 
É exatamente nessa perspectiva, que podemos compreender melhor como se dá a participação do sujeito feminino na sociedade, com uma forma de ação política diferente daquela disseminada pela militância feminista. Essa possibilidade levanta a hipótese de haver sim, a participação das mulheres com o desejo de se fazerem vistas e ouvidas, mas com formas de agência que não são, sobretudo, formuladas a partir de uma teoria feminista unificadora que designa a mulher como detentora de uma identidade única. Nesse sentido, "a identidade do sujeito feminista não deve ser o fundamento da política feminista, pois a formação do sujeito ocorre no interior de um campo de poder sistematicamente encoberto pela afirmação desse fundamento" (BUTLER, 2003, p. 23).

Quando analisamos as obras constituídas por mulheres na arte brasileira, a partir do século XX, observamos que a maneira de representação de memórias, as formas de ação, as experiências e as subjetividades de gênero não estão alinhadas com a teoria feminista, pois existe um modo de produção que não se apresenta com o mesmo teor político levantado pela militância desses movimentos. Contudo, isso não significa que tais artistas estivessem isoladas do desejo de sua autonomia como sujeitos, a superação da estrutura hierárquica patriarcal, a valorização de suas ideias/opiniões e de suas ações no seio social.

A Arte produzida por artistas mulheres no Brasil nem sempre foi alvo de pesquisas acadêmicas preocupadas em elucidar e analisar sua participação na constituição da estética nacional ${ }^{7}$, tampouco esteve em busca de compreender como a produção das obras de arte puderam, de algum modo, trazer temáticas e subjetividades que questionassem a categoria de gênero, que tivessem evidenciado a agência feminina na produção de críticas sociais ou na elaboração de questionamentos sobre as estruturas de poder estabelecidas.

Foi em busca de contribuir com a historiografia paranaense e nacional, especificamente sobre a participação das mulheres na arte, preocupando-se em diminuir essa lacuna acadêmica, que este estudo faz um recorte na produção da artista Sofia Dyminsky. Buscamos nesse sentido, compreender como o movimento moderno, no Paraná, pôde ter propiciado espaços para o questionamento sobre o papel e lugar social/político das mulheres na sociedade, seja no âmbito público ou privado, e a abordagem de subjetividades de gênero.

Dessa forma, a arte moderna paranaense vai acontecer na medida em que se aproximar da estética dos movimentos vanguardicos europeus, e dos seus desdobramentos no Brasil, que se inaugura oficialmente com a Semana de Arte Moderna de São Paulo. Teve como objetivo a renovação do pensamento artístico e literário local, não só no que diz respeito ao estilo artístico ainda atrelado aos ensinamentos de Alfredo Andersen - artista de estética naturalista e que influenciou gerações no Paraná - mas também superando os preceitos do movimento paranista, amplamente influente na concepção da arte e dos símbolos que aludiam ao paranaense e a sua identidade. Com isso, buscouse o alinhamento da produção artística paranaense as novas manifestações de arte que ocorriam em São Paulo e no Rio de Janeiro, pós Semana de Arte Moderna, acompanhando as transformações estéticas, culturais e políticas que acometiam o país e que gradativamente chegavam ao interior, dando a arte um teor social e crítico. Isso foi possível, localmente, a partir das publicações da Revista Joaquim, com a edição de textos (e obras artísticas) de ideal moderno, tanto na literatura quanto da arte, propondo a abertura de um diálogo sobre o modernismo, publicando, inclusive, textos (e obras) de intelectuais de fora do Paraná, como Carlos Drummond de Andrade e Sergio Milliet (FREITAS, 2003, p. 92).

Destarte, nas décadas de 1960/70, com o movimento feminista, as mulheres começam um intenso trabalho de afirmação como agentes políticas, dispostas a se situarem socialmente, tornando-se protagonistas de suas próprias escolhas e ações, reivindicando sua emancipação e tecendo

${ }^{7}$ TRIVOLI, T. Atravessamentos feministas: um panorama de artistas mulheres no Brasil dos anos 60/70. Tese (Doutorado em Educação) da Faculdade de Educação da Universidade de São Paulo-USP. São Paulo, p. 434. 2018 . p. 24. 
afrontamentos ao modelo patriarcal de sociedade ${ }^{8}$. Contudo, essa ação política, disseminada pelos movimentos feministas, não ocorreu da mesma forma em todos os lugares - e especialmente nas manifestações artísticas —, tampouco de maneira tão abrupta as estruturas estabelecidas. Por conseguinte, chegou de modo mais incisivo em países como o Brasil em períodos posteriores, se comparadas as produções artísticas e exposições de temáticas de gênero dos EUA e da Europa. Mesmo assim, notamos que as composições — até as atuais —, que se aproximaram das pautas feministas, tratam-se de produções mais autônomas ${ }^{9}$.

A partir desse entendimento, acredito que a arte, especialmente no Brasil durante o século XX, que apresentou cisões com os cânones ${ }^{10}$, pôde contribuir para as mulheres comunicarem assuntos, temáticas e subjetividades próprias de sua categoria de gênero, no mesmo sentido em que a Arte Moderna, ao despertar uma reflexão e crítica social, possibilitou certa liberdade no modo de expressão ${ }^{11}$. No entanto, é necessário que nós, como historiadores, problematizemos e indaguemos tais composições, para compreender de que modo elas podem comunicar determinadas características.

Entramos, dessa maneira, na questão da invisibilidade da experiência, analisada por Joan Scott, que salienta que não basta dar visibilidade a experiência, como se ela fosse uma prova incontestável, em situações que abordamos a questão da diferença, é necessário problematizá-las. Considerando esse ponto de vista, torna-se relevante trazê-lo para o campo da análise da imagem, pois corremos o risco de tornar comum diferenças representadas nas produções pictóricas devido a esse "sistema" de naturalização das experiências da diferença que a autora nos chama a atenção. Sobre isso Scott argumenta que tomamos "como autoevidentes as identidades daqueles cuja experiência está sendo documentada e dessa forma tornam-se naturais suas diferenças" (SCOOT, 1992, p. 301). Talvez seja por isso que os estudos onde são abordadas as temáticas de gênero nas obras de arte desse período, são tão raquíticos, às vezes por naturalizarem as experiências das diferenças representadas nas obras, como algo que era próprio do sexo feminino - como a dramaticidade, a expressão de sentimentos, as cenas cotidianas da casa e da comunidade - ou ainda pela forma de representação metafórica, que poderia ser usada para questionar sua condição como mulher e artista numa sociedade hierárquica.

Ainda sobre a questão da invisibilidade da experiência, em relação à representação na arte, poderíamos considerar o conceito de representar, amplamente utilizado pela Nova História Cultural,

\footnotetext{
${ }^{8}$ Ver, por exemplo, SCOTT, J. História das Mulheres. In: BURKER, P. A escrita da História. São Paulo: Unesp, 1992. p. 63-95.

${ }^{9}$ Sobre a produção das artistas latino-americanas, em relação às norte-americanas e europeias, Tvardovskas salienta que elas postura diferente (mais autônoma) não alinhadas a militância feminista de modo direto, assim como o mercado de arte, que nos EUA e na Europa iniciaram exposições com temáticas de gênero muito antes que na América Latina. Para saber mais ver: TVARDOVSKAS, L. S. Dramatização dos corpos: arte contemporânea de mulheres no Brasil e na Argentina. Tese (Doutorado em História) Instituto de Filosofia e Ciências Humanas da Universidade de Campinas UNICAMP. Campinas, p. 354. 2013. p. 45.

${ }^{10}$ Compreendendo que esses cânones estão ligados a uma série de normatizações, promovidas pelas instituições locais (escolas de arte, museus, galerias) — na arte paranaense, por exemplo, o ensino artístico a partir da estética promovida por Alfredo Andersen, e ainda as influências do movimento paranista - em ratificar tal objeto como obra artística ou não, como a representação de cunho naturalista, a representação da perspectiva, das técnicas de luz e sombra, e a abordagem de temáticas consideradas morais (apropriadas), e os sujeitos que eram originalmente considerados como "Grandes artistas" — Linda Nochlin em "Por que não houve grandes mulheres artistas?" Faz uma abordagem muito pertinente sobre o tratamento marginalizado da mulher na história da arte, onde existia o mito do "Grande Artista", cujas suas características eram determinadas pelo seu sexo, masculino, sua classe, burguesa e sua raça, branca. Ver: NOCHLIN, L. Por que não houve grandes mulheres artistas. São Paulo: Edições Aurora, 2016.

${ }^{11}$ Segundo Janson o conceito de modernnismo, amplamente presente na Arte moderna, sendo peculiar do século XX, é que possibilitou o apelo a liberdade para se criar um estilo novo e a liberdade da criação do objeto artístico, dando-lhe inclusive a missão de elaborar o significado de sua época e "reformar a sociedade através de sua arte". JANSON, H. W.; JANSON, A. F. Iniciação a história da arte. São Paulo: Martins Fontes, 1996. p. 357.
} 
para compreendermos de que modo ele foi usado pelos historiadores, estendendo-o para a análise das representações artísticas. Pesavento sobre isso salienta que:

Representar é, pois, fundamentalmente, estar no lugar de, é presentificação de um ausente; é um apresentar de novo, que dá a ver uma ausência. A ideia central é, pois, a da substituição, que recoloca uma ausência e torna sensível uma presença. A representação é conceito ambíguo, pois na relação que se estabelece entre ausência e presença, a correspondência não é da ordem do mimético ou da transparência. A representação não é uma cópia do real, sua imagem perfeita, espécie de reflexo, mas uma construção feita a partir dele (PESAVENTO, 2012, p.21).

Partindo do entendimento que a representação é uma forma de "presentificar" uma ausência, ao analisarmos uma obra pictórica — e neste caso a das artistas mulheres - em um momento cuja estrutura social privilegiava o sexo masculino, poderíamos compreendê-la como uma forma de comunicar as subjetividades, as formas de ação, e os posicionamentos femininos utilizando-se da imagem. Nesta situação, por estarem inseridas num contexto de ruptura estética, talvez tivessem maior liberdade de externalizar suas experiências e leituras de mundo, mas que devido a sua posição na sociedade patriarcal, não bastaria torná-las visíveis por intermédio da imagem, pois suas características de gênero naturalizam suas experiências da diferença, tornando a narrativa imagética "invisível", retomando o argumento de Scott.

Logo, considerando a imagem uma forma de representação e que pode sofrer os problemas da invisibilidade, especialmente quando busca representar experiências da diferença, a obra artística como fonte histórica tornar-se uma importante forma de compreender como as mulheres deixaram impressas suas ideias, opiniões, memórias e subjetividades, mas que devido a essa naturalização da diferença não tenham sido anteriormente analisadas. Nessa acepção, é muito válido o que orienta Joan Scott, sobre a necessidade de historicizar as experiências para que assim, possamos compreendê-las, não tornando a fonte, neste caso as imagens pictóricas, como autoevidentes/naturais, desnecessárias de serem esmiuçadas, interpretadas e/ou cotejadas com outros documentos/fontes. Pois, não basta tornarmo-las visíveis, é essencial que elas sejam problematizadas, para que só depois disso se tornem realmente úteis à operação histórica.

\section{Sofia Dyminsky e as Moças da Ilha: Arte moderna no Paraná e subjetividades de gênero}

Neste item faremos a análise da obra Moças da Ilha, de Sofia Dyminsky, considerando que a composição pode evidenciar aspectos da poética individual da artista, mas intrincada com a vertente moderna paranaense, além de trazer aspectos de sua experiência como mulher e artista, considerando que a imagem pode sublimar subjetividades femininas, quando analisada juntamente a outros documentos e à luz de seu contexto histórico.

Sofia Dyminski é uma artista de origem polonesa, mas que produziu sua arte no Paraná, radicada brasileira e fixando-se no estado ainda na década de 1950. Nascida em 1918, veio criança para o Brasil em 1929, acompanhada de sua família que buscava melhores condições de vida, distantes dos conflitos entre a Rússia e a Polônia ${ }^{12}$. Após fixar-se no Paraná, na região litorânea, desenvolveu uma produção autodidata. Posteriormente, em 1964, ao mudar-se para Capital, frequentou o curso de pintura de Guido Viaro, que devido sua produção de cunho moderno acabou por influenciá-la a trilhar

${ }^{12}$ ARAUJO, A. Um pedaço da Polônia na Arte de Uma mulher que lembra Mme. Curie e cuja vida daria um romance. Diário do Paraná, Curitiba, 05 de out. 1969; ARAUJO, A. Sofia Dyminski na Acaiaca. Jornal Diário do Paraná, Curitiba, 29 out. 1974; BENITEZ, A. Encarte de exposição: Sofia Dyminski, Curitiba, maio 1977. 
seu caminho estético mais próximo a esse estilo. Além do estudo com Viaro, realizou o curso "Circuito de Artes Plásticas 1964/65", ministrada pela professora Adalice Araujo, bem como o curso de gravura com o professor Fernando Calderari ${ }^{13}$, possibilitando diferentes experimentações na pintura e gravura.

Desenvolvendo-se, assim, numa poética de teor moderno e vasta efervescência cultural, devido ao cenário de ruptura local, especialmente ao movimento paranista e ao estilo estético acadêmico (de teor naturalista), onde apresentou um trabalho primoroso, contribuindo com o desenvolvimento e a consolidação do modernismo no Paraná. Simultaneamente a sua vinda para o estado, ocorria uma série de transformações no trato da arte, o que culminou na formação da segunda geração de artistas modernos, influenciados, sobretudo, pelos ensinamentos de Viaro e Lazzarotto. Teve também o sucesso das publicações da revista Joaquim, editada entre 1946-1948 por Dalton Trevisan, Erasmo Pilotto e Antônio Walger, considerada como "um divisor de águas na cultura local" (FREITAS, 2003, p. 92), e o surgimento de espaços de debate e exposições de poética moderna como a Garaginha ${ }^{14}$, a Galeria Cocaco e o Clube de Gravura ${ }^{15}$.

Nesse contexto, os artistas parananenses considerados como integrantes do modernismo da segunda geração, como Violeta Franco, Nilo Previdi, Alcy Xavier, Fernando Veloso e Loio-Pérsio, estavam dispostos a movimentar o cenário artístico local em busca de uma mudança no modo como pensar a arte, não só do ponto de vista estético, acadêmico e naturalista, mas também social, superando os estereótipos simbólicos, amplamente disseminados pela pintura paranista, pensando na produção local atrelada aos acontecimentos artísticos e sociais ocorridos nos grandes centros como São Paulo e Rio de Janeiro. Eles buscavam o reconhecimento e visibilidade local, inclusive nos Salões Paranaenses que continuavam a premiar as obras que apresentavam características alinhadas a estética acadêmica e as temáticas paranistas. A influência do Expressionismo e da estética Abstrata, por exemplo, que abordavam estilos e temáticas diferentes das que agradavam o júri dos salões de arte, nas décadas de 1950/1960, resultava em uma marginalização desses artistas, que buscavam espaço para produzir e sobreviverem de sua produção (FREITAS, 2003).

As composições produzidas por Dyminski, segundo Aurélio Benitez, são marcadas por uma expressão absoluta, onde representa paisagens das cidades litorâneas paranaenses: "Para Sofia Dyminski, o habitante do litoral é antes de tudo, um bloco de energia" (BENITEZ, 1977, s/p). Com a declaração de Benitez e a observação de suas obras, onde ela trabalha com a intensidade da cor e o uso de formas orgânicas, fica evidente a influência expressionista, provavelmente herdada de seus professores. A partir de Viáro e Araujo, pôde constituir uma estética que se diferencia do estilo estético e das temáticas da época, articulando-se com a realidade social paranaense e a novas subjetividades, como a representação das mulheres nos espaços públicos e no trabalho, causando estranhamento pela ausência dos traços fisionômicos.

\footnotetext{
${ }^{13}$ BENITEZ, A. Encarte de exposição: Sofia Dyminski, Curitiba, maio 1977.

${ }^{14}$ A Garaginha foi um espaço criado pela artista Violeta Franco, onde se reuniam artistas como Fernando Veloso, Nilo Previdi, Alcy Xavier entre outros, no período entre 1949-1951, para a produção artística e debates acerca da Arte Moderna. LIMA, M. M. A cor e a flor na obra de Violeta Franco: Arte Moderna Paranaense (1950-1980). Dissertação (mestrado em História) - Departamento de História, Universidade Estadual de Maringá - UEM. p.220. Maringá. 2016. ${ }^{15}$ FREITAS, A. A consolidação do moderno na história da arte do Paraná: anos 50 e 60 . Revista de História Regional, Ponta Grossa, v. 8, p. 87-120, Inverno 2003.
} 


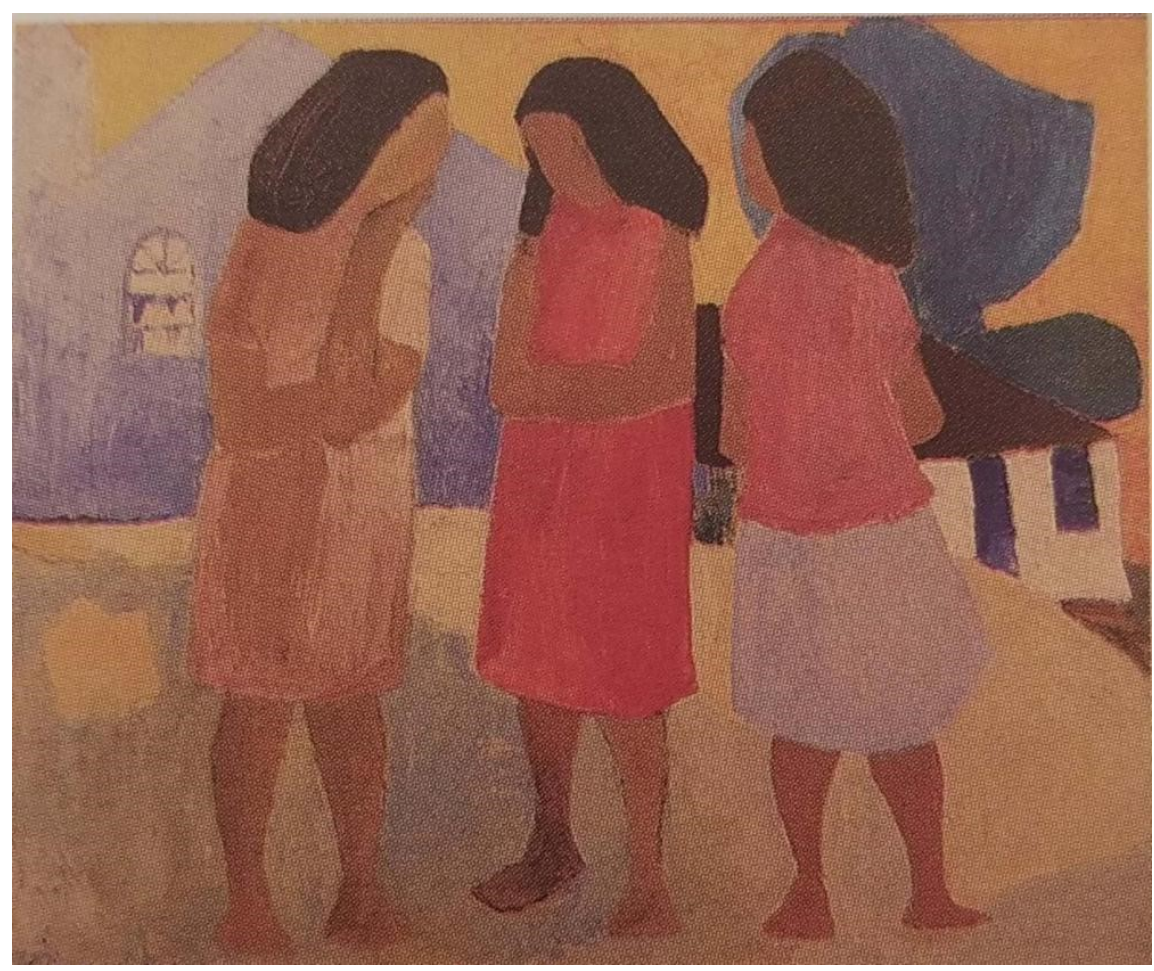

Figura 1 - DYMINSKI, Sofia, Moças da Ilha, 1964, óleo s/ tela, 70,5 x 83,9cm.

A obra aqui analisada (figura 01) é uma pintura a óleo, de porte médio, enquadrada horizontalmente, onde as cores ocres, provenientes de variações do bege no chão, e do amarelo no céu, preenchem a maior parte da composição. Os tons frios de violeta e verde aparecem contrastando com as cores quentes anteriormente sublinhadas. A tela se apresenta em três planos, sendo que no primeiro podemos perceber três personagens de estatura e gênero semelhante, dispostas em uma possível interação dialógica e centralizadas; no plano subsequente, de frente para trás, podemos identificar um cenário com duas edificações, a da direita menor em relação à esquerda, sendo possível detectar uma árvore atrás da casa menor; em terceiro plano percebemos apenas o horizonte, a partir da sugestão de um céu limpo, sem nuvens, pássaros ou astros.

A forma simplificada como a artista delineia seus personagens e objetos, sem linhas muito bem definidas, compondo as formas a partir da cor e com pequena quantidade de detalhes, aproximam sua poética ao Expressionismo Alemão ${ }^{16}$, sendo que o uso de tonalidades como o amarelo e o vermelho, em contraste com o violeta e o verde, remetem levemente ao Fauvismo Francês ${ }^{17}$.

As três personagens que dividem o protagonismo da representação são mulheres, provavelmente mestiças devido suas características étnicas, pois, apresentam traços estereotipados da fisionomia negra, como o tom de pele mais escura, porém mulata, evidenciando a miscigenação com outras raças, bem como os cabelos lisos, possivelmente se relacionando a miscigenação com o indígena ou europeu. Tais relações podem ser sugeridas, pois, a crítica de arte Adalice Araujo, em vários artigos

\footnotetext{
${ }^{16}$ Movimento artístico iniciado na Alemanha, subdividido em dois grupos de atuação. Der Blaue Reiter e Die Bruck. Baseados na expressão da forma e contrários a conotação de impressão do Impressionismo desenvolvem suas obras num "processo em que as cores e as formas se tronam depositárias da ideia pictórica. MEIRA, S. M. Imagem moderna: um olhar. Belo Horizonte, C/ Arte, 2006. p. 39.

${ }^{17}$ Movimento artístico iniciado na cidade de Paris, reagindo à estética impressionista. Recebeu esse nome devido à crítica de Louis Vauxcelles, na ocasião do Salão de Outono de 1905, que foram chamados por ele de les fauves (as feras) considerados violentos tanto nas pinceladas como no uso das cores puras, e simplicidade na representação das formas. Um dos expoentes do grupo foi Henri Matisse. Para saber mais ver: MEIRA, S. M. Imagem moderna: um olhar. Belo Horizonte, C/ Arte, 2006.
} 
ao jornal Diário do Paraná, destaca o apreço que Dyminski apresenta pela arte regional, folclórica e pré-histórica, ilustrando os povos locais como os índios e caboclos ${ }^{18}$

A análise, além de destacar aspectos que se relacionam a inovação estética, presente na ruptura com os cânones acadêmicos, também se ocupa das subjetividades que englobam as questões de gênero, como as relações de poder, agência e temáticas sociais, bem como a história, evidenciando questões da memória, da identidade e da cultura paranaense, ressaltadas de modo direto ou subjetivo. No que se refere à questão de gênero e suas intersecções com a história, o interesse não é simplesmente ressaltar o pioneirismo no movimento feminista na política e os reflexos que tais articulações promoveram na arte, mas levantar questionamentos a partir de suas diversas temáticas. Será considerada a condição da artista como mulher, inserida numa sociedade patriarcal, onde desempenha múltiplos papéis como esposa e mãe, mas, sobretudo, cidadã que é detentora de vontades e desejos, podendo tomar posicionamentos, tecer críticas ou simplesmente produzir narrativas imagéticas que salientem aspectos da vida cotidiana.

Sobre essas diferentes atividades desempenhadas pela mulher, especialmente no período moderno, onde além das atribuições domésticas algumas enfrentam o mercado de trabalho e as contradições entre ser livre, geradora de renda, mas simultaneamente presa as tradições sociais que ligam a mulher a certas responsabilidades, a reflexão de Hall sobre identidade parece pertinente:

A identidade plenamente unificada, completa, segura e coerente é uma fantasia. Ao invés disso, à medida que os sistemas de significação e representação cultural se multiplicam, somos confrontados por uma multiplicidade desconcertante e cambiante de identidades possíveis, com cada uma das quais poderíamos nos identificar ao menos temporariamente (HALL, 2001, p. 13).

Neste sentido, as representações imagéticas poderão trazer essas contradições identitárias, nas quais as mulheres estiveram e ainda estão submetidas, entre os anseios de se fazerem ouvidas, para terem suas atividades valorizadas e a exigência de uma postura socialmente passiva, se inteirando apenas das atribuições domésticas. Muitas vezes essas normatizações sociais não se importar com seus posicionamentos e vontades, suas ideias e críticas, seja na vida pública ou privada, tornando, assim, suas experiências naturalizadas, ou seja, invisíveis e menos importantes do que as atividades e tarefas realizadas pelo sexo masculino.

A intenção deste trabalho, nessa perspectiva, não é definir uma identidade universal da mulher (paranaense) artista, moderna e feminista, pois seria até utópico idealizar uma identidade una e militante das mulheres paranaenses nesse período, — pois como argumenta Hall elas podem em vários momentos serem múltiplas. Entretanto, busca-se evidenciar a atuação da artista Sofia Dyminski em relação aos outros sujeitos, homens, mulheres e companheiro(a)s de ofício, especialmente a partir da segunda metade do século XX, historicizando as questões socioculturais e relacionadas ao gênero, engendradas em suas representações pictóricas.

A pesquisadora Luana Saturino Tvardovskas (2013) destaca que a relação entre arte e feminismo, do Brasil, de maneira direta, cujas artistas se auto designam feministas é raro. Contudo, não quer dizer que as representações pictóricas dessa época estiveram alheias as questões relacionadas a essa temática. Nas produções de artistas da modernidade paranaense, podemos observar que o espírito militante combativo, alinhado com o movimento feminista não ocorre de modo explícito, mas as

${ }^{18}$ ARAUJO, A. Um pedaço da Polônia na Arte de Uma mulher que lembra Mme. Curie e cuja vida daria um romance. Diário do Paraná, Curitiba, 05 de out. 1969; ARAUJO, A. Sofia Dyminski na Acaiaca. Jornal Diário do Paraná, Curitiba, 29 out. 1974 
mulheres artistas, em inúmeros trabalhos, apresentam subjetividades que se preocupam com as relações sociais e temáticas do cotidiano feminino ${ }^{19}$.

Nas obras de Sofia Dyminski, como a apresentada acima, é comum observar o uso de algumas subjetividades que são recorrentes em momentos distintos de sua produção, como a representação da paisagem, seja ela urbana ou natural (do litoral paranaense), bem como a figura de mulheres, amplamente exploradas nos cenários paisagísticos, podendo estar em relação com a figura masculina, em situação de trabalho ou apenas em interação entre outras mulheres, como na tela "Banhistas do Nhundiaquara" (figura 02) e "Tarde de Laser" (figura 03).

Na tela Moças da ilha é possível identificar que as personagens estão em uma paisagem urbana, no espaço público, aparentemente em um encontro casual entre mulheres conhecidas que fazem uma pausa no meio da rua para cumprimentar-se, e que desse momento, gera-se um diálogo. Pelo comportamento corporal das mulheres é possível perceber que o assunto é curioso/surpreendente, pois a personagem da esquerda coloca a mão sobre a boca como se estivesse surpresa com o que ouvia, enquanto a mulher da direita, que aparentemente estava de passagem, volta-se com seu corpo para as outras duas como se quisesse ouvir melhor o diálogo. A personagem do meio apresenta-se com uma postura tensa, de braços cruzados e simultaneamente cabisbaixa, com a cabeça levemente inclinada para baixo.
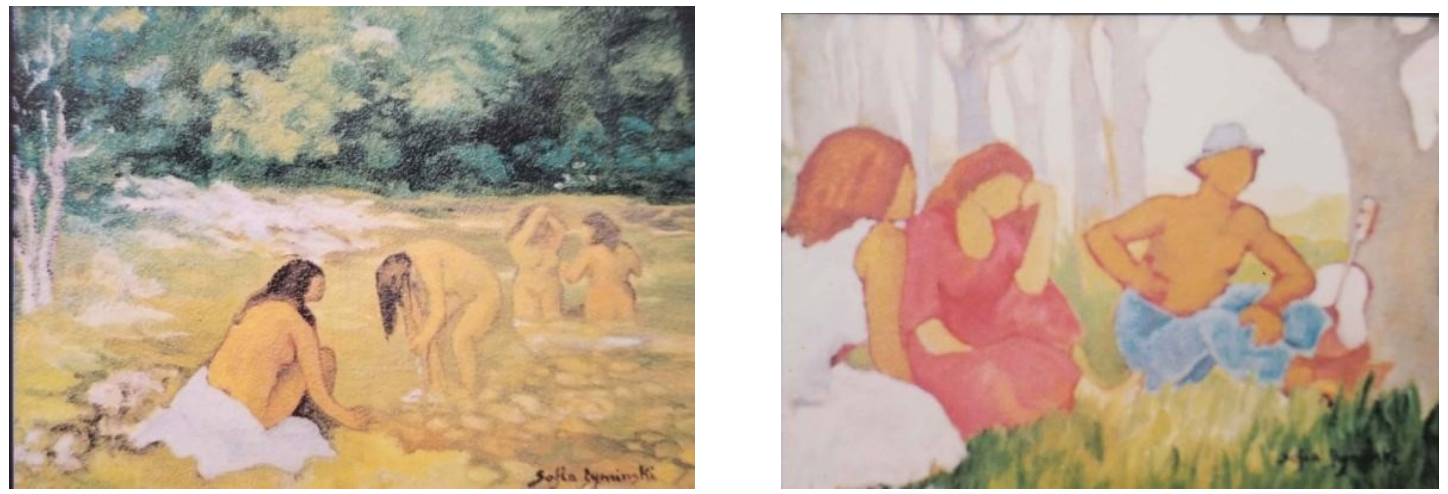

Certamente, não é possível saber com exatidão o que se passava naquele diálogo, pois as narrativas imagéticas em certas ocasiões, mais sugerem do que esclarecem certos fatos e memórias, no entanto, se analisarmos os símbolos presentes na imagem a partir do que Erwin Panofsky chamou de Iconologia, é exequível compreender de maneira mais consistente, mas não determinativa, a mensagem que a artista procura demonstrar em sua representação. Sobre isso Panofsky salienta:

Assim, a esfera em que o campo dos objetos práticos termina e o da arte começa, depende da "intenção" de seus criadores. Essa "intenção" não pode ser absolutamente determinada. Em primeiro lugar, é impossível definir as "intenções", per se, com precisão científica. Em segundo, as "intenções" daqueles que produzem objetos são condicionadas pelos padrões da época e meio ambiente em que vivem (PANOFSKY, 2012, p. 32).

\footnotetext{
${ }^{19} \mathrm{Na}$ minha dissertação de mestrado trabalhei com a análise das obras de Violeta Franco (paranaense), uma artista moderna, contemporânea a Dyminski, cuja poética enalteceu temáticas relacionada as subjetividades femininas, como a valorização do corpo e a representação da mulher com a natureza, além de destacar sua importância enquanto mãe, que gera a vida, percebidas nas figuras que insinuam o fruto/semente na natureza e o útero na mulher. Essas características demonstram que não só Dyminski, mas outras artistas já se preocupavam com aspectos da feminilidade, no Paraná, embora não tenham levantado a bandeira de movimentos feministas. AUTOR XXXXX M. NOME DA OBRA, 2016
} 
A partir do que argumenta o autor, se faz importante observar questões ligadas ao momento e lugar ${ }^{20}$ que foram criadas as representações para que a análise possa se aproximar da maneira mais próxima possível da intenção de sua autora. Panofsky ainda ressalta que além dessa preocupação, ligada ao lugar e época da artista, nós como observadores/analistas/avaliadores, também somos influenciados; "nossa avaliação dessas intenções" é, inevitavelmente, influenciada por nossa própria atitude, que por sua vez, depende de nossas experiências individuais, bem como de nossa situação histórica" "21. Desse modo, ao realizar uma análise historiográfica, no qual a narrativa busca evidenciar questões ligadas ao social, cultural e automaticamente a história de determinado tempo, indivíduo ou sociedade, o historiador elege suas matérias e realiza determinadas escolhas, buscando resolver algum problema e verificar hipóteses, como destaca Febvre ${ }^{22}$.

Nesse sentido, a partir das subjetividades, não só da obra em análise, mas verificadas em outras produções (figuras 02 e 03), como o interesse da artista pela representação da figura feminina, o apreço pela paisagem litorânea e pela imagem do caboclo, é crível historicizar essas imagens, interpretando as formas elaboradas na composição em busca de seu conteúdo, ou pelo menos, parte dele. É o alinhamento com críticos de arte como Adalice Araujo e Aurélio Benitez, contemporâneos da artista e que em diferentes ocasiões puderam estar juntos de Dyminski, escrevendo sobre sua produção, que nos possibilita relacionaremos o conteúdo estético - formas, linhas cores e símbolos-, com o conteúdo social proposto na obra. Sobre a relação entre ideia e forma, Panofsky destaca:

Uma coisa, entretanto, é certa: quanto mais a proporção de ênfase na "ideia" e "forma" se aproxima de um estado de equilíbrio, mais eloquente a obra revelará o que se chama "conteúdo. Conteúdo, em oposição a tema, pode ser descrito nas palavras de Peirce como aquilo que a obra denuncia, mas não ostenta. É a atitude básica de uma nação, período, classe, crença filosófica ou religiosa - tudo isso qualificado, inconscientemente, por uma personalidade e condensada numa obra (PANOFSKY, 2012, p. 33.

A partir da iconologia de Panofsky, faremos então a análise histórica do conteúdo da obra, Moças da Ilha, considerando as imagens (formas, signos e cores) que possam evidenciar, de algum modo, as intenções ou mensagens presentes na composição. Logo, um dado importante de ser observado nesta obra é a representação da figura feminina na vida pública, ou seja, além das atividades domésticas realizadas no âmbito privado, dentro de suas casas. Essa subjetividade da poética da artista, como podemos notar, é frequentemente demonstrada em suas composições (como nas figuras 02 e 03). Na Obra As banhistas de Nhundiaguara, também podemos notar a interação só entre mulheres, banhando-se em um rio, aparentemente livres e despreocupadas com os julgamentos que poderiam sofrer por estarem totalmente despidas, fora de seus lares, em um local que embora afastado, em meio a natureza, é público. Tais características, recorrentes, puderam evidenciar o desejo da artista em demonstrar a vida da mulher no âmbito da coletividade pública, valorizando assim, suas atividades e presença no seio social

\footnotetext{
${ }^{20}$ Sobre isso é importante considerarmos o que destaca Certeau: "Toda pesquisa historiográfica se articula com um lugar de produção socioeconômico, político e cultural [...] É em função deste lugar que se instauram os métodos, que se delineia uma topografia de interesses, que os documentos e as questões, que lhes serão propostas, se organizam.”: CERTEAU, M. D. A escrita da História. $1^{\text {a }}$. ed. Rio de Janeiro: Forense Universitária, 1982.

${ }^{21}$ PANOFSKY, E. O significado das artes visuais. $3^{\circ}$. ed. São Paulo: Perspectiva, 2012. p. 32-33.

${ }^{22}$ FEBVRE, L. Combates pela história. Lisboa: Editorial Presença, 1989.
} 


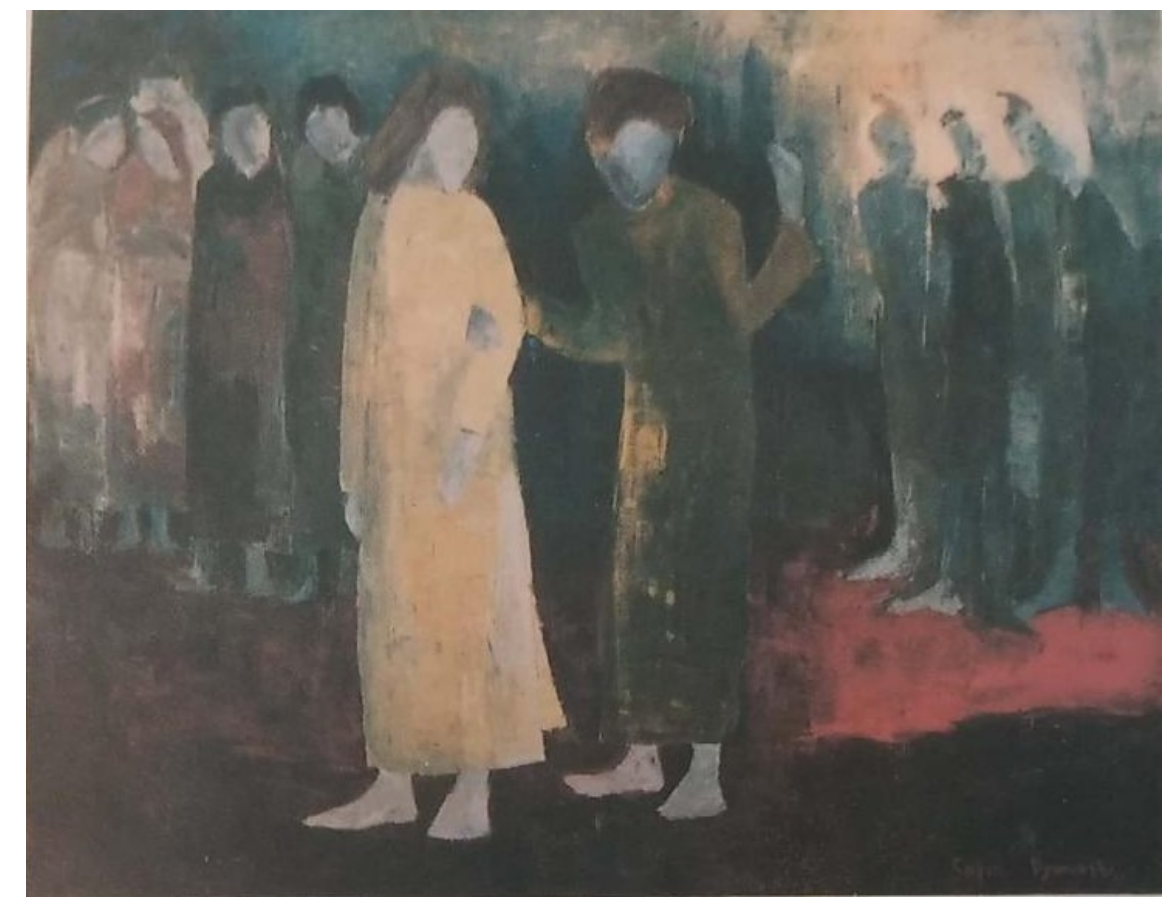

Partindo, agora, para possíveis símbolos/signos, presentes na composição Moças da ilha, podemos observar que a construção localizada do lado esquerdo, a maior, trata-se de uma igreja, devido o seu tamanho em relação às outras e, também, pelo fato de haver uma forma, à esquerda, que sai da base da construção, ultrapassando a altura do telhado, insinuando a imagem de uma torre.

O significado da igreja, ao longo dos tempos e dependendo da época, pode agregar várias significações. Segundo o dicionário de símbolos de Jean Chevalier $^{23}$, a igreja, na tradição cristão, simboliza o mundo, bem como Jerusalém, o reino dos escolhidos e está designando, também, a alma humana, a esposa de cristo e mãe de todos os cristãos. A artista, ao representar as mulheres em frente à Igreja, que na maioria das cidades está localizada em um local privilegiado, no centro, gostaria, mesmo de modo inconsciente como descreve Panofsky, dar maior visibilidade e importância as personagens. Adalice Araujo em 1974, em artigo escrito ao jornal Diário do Paraná, lembra que a questão da religiosidade estava frequentemente presente em suas representações. Esse interesse também pode ser visto na tela A traição de Judas de 1966 (figura 04).

A partir desse interesse pela religiosidade e como detentora da fé cristã, ao colocar as mulheres em frente a um "monumento" religioso - que se encontra destacado mesmo que em segundo plano, de maneira facilmente notável - , consciente ou não, a artista introduz as mulheres, por analogia, não só no centro da tela, mas também como participativas no seio social. Afinal, estão diante de uma construção com amplos significados, como o mundo e a Jerusalém, símbolo primordial do cristianismo. Nessa senda, colocando-as diante dessa construção, poderia reafirmar a posição importante da mulher, ilustrando-as num cenário privilegiado, um lugar de destaque, central e não em escanteio, como muitas vezes as mulheres poderiam ser colocadas numa sociedade patriarcal. A partir dessas evidências, é possível atrelarmos o posicionamento da imagem diante da igreja, como uma forma de dar protagonismo as mulheres, as suas ações e atividades.

Além disso, temos outros símbolos que se destacam, como a imagem da janela, presente na construção religiosa, que é colocada de modo que chama a atenção do espectador, sendo impossível não notá-la. No momento em que remetemos nosso olhar para as mulheres, a janela surge ladeando-

\footnotetext{
${ }^{23}$ CHEVALIER, J. Diccionario de los Símbolos. Barcelona: Herder, 1986. p.589.
} 
as, confundindo, inclusive, nosso olhar, como se num primeiro momento estivesse igualmente em primeiro plano. Este símbolo está atrelado a receptividade do ar e da luz, bem como a da consciência, quando redonda, e a terrena, respeitando o celestial, quando quadrada ${ }^{24}$. O destaque à janela ao fundo - em uma composição moderna que despreza grande parte dos detalhes -, mas que em um olhar mais rápido confunde-se com o primeiro plano, pode remeter a significações relevantes, sendo assim, mais que uma simples alegoria. Estando ela presente na construção da igreja, que simboliza o mundo, atrelada a significação de receptividade, é possível ligar a imagem das personagens femininas em primeiro plano, a um cenário de inclusão das mulheres no seio social. A janela, por apresentar uma forma híbrida, circular em cima e quadrada embaixo, sugere a receptividade da consciência e também a da vida terrena, sendo que o fato das personagens estarem dialogando, pode remeter a importância de seu discurso, ideias e opiniões diante da sociedade.

Outro aspecto importante é a data da produção da obra, o ano de 1964, um período de tensão política, econômica e social, devido à queda de João Goulart e início do Governo Militar. Embora não seja possível atrelar o diálogo das mulheres a esse acontecimento político, tal tratativa pairaria o imaginário social da época. $\mathrm{O}$ aspecto preocupado de uma das mulheres e o de surpresa da outra, provavelmente nos dá um indício da situação ou diálogo inusitado. Isso se torna mais evidente ao percebemos a terceira mulher à direita, que até faz uma parada quando passava diante das outras, para ouvir. Tal ação é nitidamente notada pela posição do corpo em deslocamento e a impressão da cabeça sendo projeta rapidamente para trás.

Todo esse conjunto de significações, atreladas ao contexto de produção paranaense, que estava em efervescência, ampliando as possibilidades de inovação, a partir da proposição de uma estética moderna, destacada por Freitas, proporciona que a arte mude além da estética, mas que proponha reflexões e críticas sociais. A própria forma como ela representa as mulheres, em tamanho grande, ilustradas em primeiro plano, sem a identificação de traços fisionômicos - outra subjetividade da artista, onde os rostos não apresentam feições - pode levar a uma interpretação, na qual seu desejo é incluir e valorizar as mulheres, colocando-as em destaque numa cena pública e em relação dialógica. Ela valoriza o discurso feminino ao ilustrá-las em frente a uma Igreja, edificação que denota fortes significações históricas e culturais, inclusive como sendo "o mundo" e/ou a região central de uma cidade.

Ademais, podemos compreender que mesmo as mulheres pertencendo a uma cultura masculina, dominante, há um desejo de se fazerem ouvidas e valorizadas, inclusive na cena pública. Sobre isso Cuche argumenta: "Uma cultura dominante não pode se impor totalmente a uma cultura dominada [...] A dominação cultural nunca é total e definitivamente garantida [...], pois sofrer a dominação não significa, necessariamente, aceitá-la" (CUCHE, 1999, p. 148). Deste modo, a obra artística e as relações simbólicas presentes na imagem, podem nos levar a compreender o desejo dessa artista mas não só o dela —, de que a mulher também tenha um espaço importante (no centro, não melhor que o homem, mas no mesmo patamar) na organização cultural. As mulheres, nesse sentido, não nutriam o desejo de invisibilidade, mas de tornar de algum modo, suas experiências visíveis, independente se a sociedade iria naturalizá-las ou notá-las. Há então, uma lógica no que defende Cuche, pois as culturas dominadas não são totalmente passivas, existem possibilidades de discordar e rechaçar o status dominante e a produção artística, no meu entendimento, pode ser uma dessas formas.

${ }^{24}$ CHEVALIER, J. Diccionario de los Símbolos. Barcelona: Herder, 1986. p. 1055. 


\section{Considerações Finais}

Este trabalho buscou, a partir da análise da obra Moças da Ilha (1964), de Sofia Dyminsky, compreender como a produção artística pode evidenciar subjetividades femininas, fazendo um recorte na arte moderna paranaense. A produção da artista, dialoga com a produção moderna produzida no Paraná, justamente pela sua proposta de abordagem expressionista, que não estivesse arraigado ao naturalismo (aos modelos canônicos) como a distorção e/ou ausência das feições faciais, algo expressivo na composição analisada. A arte moderna, inclusive a produzida pela artista, além de propor uma ruptura com os padrões acadêmicos, investe numa ampliação da noção do que é produzir um objeto artístico belo/estético, cuja as subjetividades e as relações entre artista, espectador e meio possam despertar uma consciência critica, política e humanística.

Sofia Dyminski torna possível essa proposição estética moderna, pois avança para uma cisão com o cânone, ampliando a noção (estética) de beleza, realizando uma reflexão social, a partir da abordagem de temáticas diferentes do que se habituava no contexto paranaense da época, bem como a simplificação das formas, sobretudo das feições. Rompe, ainda, com os símbolos/estética/ideologias provenientes do paranismo, da representação da mulher como polo passivo e do corpo e ação feminina como algo que transitava, comumente, apenas numa esfera privada e doméstica, sem intenções políticas.

Ademais, as pesquisas que buscam compreender como a produção de artistas mulheres podem narrar experiências, seus desejos e críticas ainda são escassos, tornando essa área de atuação, que trabalha as categorias de gênero, como uma importante fonte de análise. A arte, em diversos momentos, traz à tona, percepções do mundo, representações de experiências e fatos, e quando não, trabalha com os desdobramentos destes, externalizando através da imagem, memórias, sentimentos e desejos que podem contribuir para a compreensão das categorias de gênero, como é o caso deste estudo.

Além disso, a obra de arte pode ser analisada de diferentes frentes, tornando-se uma fonte possível de ser interpretada e historicizada, pois em muitos momentos a arte ao tentar dar visibilidade a temas e questões que tratam da diferença, por ser uma atividade amplamente ligada ao imaginário e o fantástico, pode ter naturalizado denúncias, críticas e sentimentos, como algo comum e "exclusivo" da atividade pictórica. Nesse ponto, a análise de Scott sobre a invisibilidade da experiência da diferença, pode ser estendida para compreender a produção artística, pois assim como as experiências da diferença podem ser naturalizadas e tornadas invisíveis, as obras artísticas também correm esse risco, especialmente devido seu teor subjetivo, sugestivo e imaginativo. É por isso que uma análise imagética, atrelada ao contexto histórico e com o compromisso do trabalho do historiador, torna-se tão importante, pois a partir de seus cuidados e métodos que é possível a análise dessas narrativas.

Logo, o historiador atento as subjetividades encontradas em tais produções, tem a possibilidade de confrontá-las com o contexto histórico e com outras fontes, para assim decidir se essas composições esclarecem questionamentos pertinentes ao seu objeto de estudo ou se levará a novas perguntas. De maneira geral, a arte, seja a partir da pintura ou de outras linguagens, tem o potencial de contribuir com o historiador em seu trabalho, pois narra, comunica e expressa, algumas vezes mais objetivamente, outras subjetivamente, mas são resultados de interações que ocorreram em um lugar social e em um determinado momento. 


\section{Referências}

ARAUJO, A. Um pedaço da Polônia na Arte de Uma mulher que lembra Mme. Curie e cuja vida daria um romance. Diário do Paraná, Curitiba, 05 de out. 1969.

ARAUJO, A. Sofia Dyminski na Acaiaca. Jornal Diário do Paraná, Curitiba, 29 out. 1974.

BENITEZ, A. Encarte de exposição: Sofia Dyminski, Curitiba, Maio 1977.

BOSI, A. Reflexões sobre a Arte. $7^{\mathrm{a}}$. ed. São Paulo: Ática, 2004.

BURKE, P. Abertura: A Nova História, seu passado e seu futuro. In: BURKE, P. A Escrita da História. São Paulo: Unesp, 1992. Cap. 01, p. 07-37.

BUTLER, J. Problemas de gênero: feminismo e subversão da identidade. Rio de Janeiro: Civilização Brasileira, 2003.

CERTEAU, M. D. A escrita da História. 1ª ed. Rio de Janeiro: Forense Universitária, 1982.

CHARTIER, R. A beira da Falésia: a história entre incertesas e inquietudes. ${ }^{\mathrm{a}}$. ed. Porto Alegre: Universidade Federal do Rio Grande do Sul , 2002b.

CHEVALIER, J. Diccionario de los Símbolos. Barcelona: Herder, 1986.

CUCHE, D. A Noção de Cultura nas Ciências Sociais. Bauru: EDUSC, 1999.

DYMINSKI, S. Exposição Individual :Eucap Expo. Museu de Arte Contemporânea (MACPR), Curitiba. Encarte de Exposição, Maio 1977.

FEBVRE, L. Combates pela história. Lisboa: Editorial Presença, 1989.

FREITAS, A. A consolidação do moderno na história da arte do Paraná: anos 50 e 60 . Revista de História Regional, Ponta Grossa, v. 8, p. 87-120, Inverno 2003. ISSN 2.

GOMBRICH, E. Arte e Ilusão: Um estudo da psicologia da representação pictórica. 4. ed. São Paulo: Martins Fontes, 2007.

HALL, S. A Identidade Cultural na Pós-modernidade. Rio de Janeiro: DP\&A, 2001.

HARTOG, F. Regimes de Historicidade: presentismo e experiências do tempo. Belo Horizonte: Autêntica, 2014.

JANSON, H. W.; JANSON, A. F. Iniciação a história da arte. São Paulo: Martins Fontes, 1996.

KOSELLECK, R. Futuro passado: contribuição à semântica dos tempos históricos. Rio de Janeiro: PUC-Rio, 2006.

LIMA, M. M. A cor e a flor na obra de Violeta Franco: Arte Moderna Paranaense (1950-1980). Disertação (mestrado em História) - Departamento de História, Universidade Estadual de Maringá UEM. Maringá, p. p. 220. 2016.

MEIRA, S. M. A imagem moderna: um olhar. Belo Horizonte: C/Arte, 2006.

NOCHLIN, L. Por que não houve grandes mulheres artistas. São Paulo: Edições Aurora, 2016.

PANOFSKY, E. O significado das artes visuais. $3^{\circ}$. ed. São Paulo: Perspectiva, 2012.

PESAVENTO, S. J. História e História Cultural. Belo Horizonte: Autêntica, 2012.

POLLOCK, G. Visión y diferencia: Feminismo, feminidad e historias del arte. Buenos Aires: Fiordo, 2019.

SCOTT, J. História das Mulheres. In: BURKER, P. A escrita da História. São Paulo: Unesp, 1992. p. 63-95. 
TRIVOLI, T. Atravessamentos feministas: um panorâma de artístas mulheres no Brasil dos anos 60/70. Tese (Doutorado em Educação) da Faculdade de Educação da Universidade de São Paulo - USP. São Paulo, p. 434. 2018.

TVARDOVSKAS, L. S. Dramatização dos corpos: Arte contemporânea de mulheresno Brasil e na Argentina. Tese (Doutorado em História) Instituto de Filosofia e Ciências Humanas da Universidade de Campinas - UNICAMP. Campinas, p. 354. 2013. 